\title{
Male involvement in family planning: A KABP study of Agra District, Uttar Pradesh
}

\author{
M.E. Khan \\ Population Council \\ Bella C. Patel \\ Population Council
}

Follow this and additional works at: https://knowledgecommons.popcouncil.org/departments_sbsr-rh

Part of the Family, Life Course, and Society Commons, and the International Public Health Commons How does access to this work benefit you? Let us know!

\section{Recommended Citation}

Khan, M.E. and Bella C. Patel. 1997. "Male involvement in family planning: A KABP study of Agra District, Uttar Pradesh," Asia and Near East OR/TA Project Final Report. New Delhi: Population Council. 
MALE InVOLVEMENT IN FAMILY PLANNING A KABP Study of Agra District Uttar Pradesh

M. E. Khan

Bella C. Patel NeW DeLhI

June 1997 


\title{
MALE INVOLVEMENT IN FAMILY PLANNING
}

A KABP study of Agra District

\author{
INDIA
}

Final Report

M. E. Khan

Bella C. Patel

\section{POPULATION COUNCIL}

June 1997 
"Changes in both men's and women's knowledge, attitudes and behaviour are necessary conditions for achieving the harmonious partnership of men and women. Men play a key role in bringing about gender equality since, in most societies, men exercise preponderant power in nearly every sphere of life ... . It is essential to improve communication between men and women on issues of sexuality and reproductive health, and the understanding of their joint responsibilities, so that men and women are equal partners in public and private life."

ICPD Programme of Action 


\section{CONTENTS}

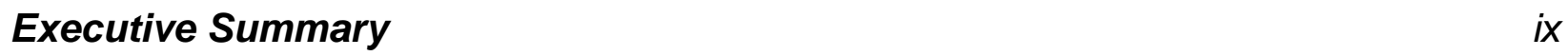

$\begin{array}{ll}\text { Introduction } & 1\end{array}$

$\begin{array}{ll}\text { Objectives of the Study } & 3\end{array}$

$\begin{array}{ll}\text { Data } & 4\end{array}$

$\begin{array}{lr}\text { Findings } & 4\end{array}$

Profile of the respondents 4

Access to mass media $\quad 6$

Ideal family size norm $\quad 6$

Attitude of Respondents about Various Reproductive

Decision Making Processes $\quad 8$

Perceived ideal age at marriage $\quad 8$

Husband-wife communication $\quad 8$

Decision making in family formation $\quad 11$

$\begin{array}{ll}\text { Family Planning } & 13\end{array}$

Knowledge, attitude and practice of family planning 13

Attitude towards family planning $\quad 14$

Current use of contraceptives $\quad 15$

Purpose of contraception and method used 16

Past Use $\quad 16$

Unmet need of family planning 17

Why men prefer tubectomy over vasectomy? 17

Reasons why condom use is low? $\quad 21$

Awareness of legal status of abortion and its approval 23

\begin{tabular}{l|l} 
References & 27
\end{tabular} 


\section{LIST OF TABLES}

1 Socio-economic characteristics of the couples 5

2 Access to media 6

$\begin{array}{lll}3 & \text { Ideal number of children } & 7\end{array}$

$4 \quad$ Perception about time when a girl should get married $\quad 8$

$5 \quad$ Husband-wife communication on reproductive matters 9

$6 \quad$ Male perception on what discourages spouses from discussing contraception and number of children at an early stage of married life

$7 \quad$ Perceived reaction of men, if their wives initiate discussion on their reproductive intentions soon after marriage

8 Who decides in the family about various reproductive behaviour

9 Awareness and correct knowledge of men and women about different family planning methods

10 Current use of contraceptive 15

11 Reasons why tubectomy is preferred over vasectomy 18

12 Reasons for shift from vasectomy to tubectomy 19

13 Comparison of males' attitude towards vasectomy and tubectomy

14 Reasons for preferring tubectomy over vasectomy 20 as given by sterilized couples

15 Reasons for disapproving MTP

16 Approval of abortion by knowledge of the legal status of abortion in India 


\section{LIST OF FIGURES}

1 Percentage of vasectomies to total sterilization, 1956-1995 2

2 Exposure of men and women to number of mass media (M.M.) 6

$\begin{array}{lll}3 & \text { Perceived ideal number of sons and daughters } & 7\end{array}$

4 Percentage correctly aware of the legal age at marriage for girls and boys

5 Who should initiate discussion on reproductive goals or contraception 10

6 Who decides when or which doctor to be consulted 12

$7 \quad$ Approved of FP and timing when contraceptive could be used

8 Purpose of contraceptive and method used 16

$9 \quad$ Level of unmet need 17

10 Suggestions to popularize vasectomy 21

11 Reasons why condoms are not used 22

12 Reaction to unwanted pregnancy of male and female respondents not wanting any more children 24

13 Awareness of the legal status of abortion 24

14 Approval of abortion 25 


\section{EXECUTIVE SUMMARY}

The present paper addresses to the knowledge, attitude, belief and practices of rural males towards various aspects of family formation including reproduction and contraceptive use. The study was undertaken in the rural areas of Agra district, located in western parts of Uttar Pradesh. To assess the knowledge and attitude of the males, altogether 517 currently married males, whose wives were in the reproductive age (13-49 years) were randomly selected and interviewed. Out of 517 males who were interviewed, in 317 cases their wives were also interviewed about a month before the male survey. The two sets of data gave an opportunity to compare the attitude of males and females on selected issues related with family formation. The following gives the salient findings.

1. The study shows that while nine out of ten men were exposed to at least one mass media and four out of ten to three or more sources of information, the corresponding number in the case of women were limited to three and one respectively.

2. On an average both men and women want three children - two sons and a daughter. However, it was also noted that slightly less than one-third of the males (31 percent) as well as females (29 percent), preferred four or more children.

3. Son preference was shown both by men and women, but it was slightly stronger among men than their wives. For instance, about one-fourth of the men as against about one-third of the women felt that they would be satisfied with only one son. Overall, the study shows that the desired family size is still large (three or more) and concept of two child family has not been accepted by majority of the couples.

4. One-third of the men and more than two-thirds of the women were not correctly aware of the legal age at marriage for girls. Further, a sizeable proportion (35 percent) of the men and (46 percent) of the women still believe that ideally girls should be married at young age, preferably before completing 17 years of age.

5. The study reveals major lack of communication between the husband and the wife on their reproductive goals and acceptance of contraceptive. More than half of the men reported no communication or discussion with their wives on their reproductive goals. And, whenever it occurred, it was initiated by the husband - that too after having two or three children.

6. On-fourth of the men believed that reproduction is a natural process and need not be discussed. An equal proportion felt that these are meaningless things and do not help in any way. About two-thirds of the males (65 percent) believed that discussion on these issues should be always initiated by men/husbands. 28 to 34 percent also felt that they would be offended and would react adversely if their 
wives take initiative to discuss either on reproductive goals or contraceptive use.

7. 38 to 52 percent of the men said that in their families all decisions related to reproduction and family planning were taken by husband alone. Another half felt that decisions were generally taken jointly with wife while very few (less than 10 percent) felt that women alone could take such decisions.

8. The study also reveals that most of the men and women are aware of vasectomy, tubectomy, pills and condom. However, only about 44 percent of the men as compared to 72 percent of the women were aware of the IUD. Except condom, in the case of all other contraceptives, less than half of the male respondents had correct knowledge as to how the method is used. Only 18 percent of the males had correct knowledge of IUD.

9. While most (85 percent) of the men approved family planning, majority (56 percent) felt that it should be adopted only after having two children. Knowing fully well that without husband's permission a woman cannot adopt any contraceptive, such conditional approval of contraception by males could be a serious bottleneck in the acceptance of contraceptive at low parity or its use for spacing purposes.

10. While, according to the husband's interview, 33 percent of the couples were using modern family planning methods, only 20 percent of their wives reported use of contraceptive. Wide gap was observed in the case of condom use (10 percent reported by men as compared to 4 percent by women).

11. Use of contraceptive for spacing purpose is still an alien concept as most of the acceptors (79 percent were using family planning for stopping childbearing. About 42 percent of the family planning users were depending on non-terminal methods, largely condom and pills, for limiting childbearing.

12. The study thus reveals that most of the men, who adopt family planning, do so for stopping childbearing and even among those, four out of ten prefer to use nonterminal methods. This indicates that the general programme emphasis on promoting sterilization, even among those having many children, may not succeed in motivating a substantial proportion of couples with unmet need for limiting children. This underlines the need of offering a wide range of contraceptives so that they could have choice as well as possibility of switching over from one method to other, if they desire so. Adding of contraceptives like DMPA (injectable), Diaphragm and non-scalpel vasectomy, the programme could provide some more choice of methods to prospective family planning acceptors.

13. The total unmet need as reported by men was only 29 percent as compared to 39 percent reported by the women. This gap was mainly because very few men expressed unmet need for spacing. The stated unmet need for limiting child- 
bearing was almost identical. This indicates that men are less concerned about spacing between births than women.

14. A probing on why men prefer tubectomy over vasectomy revealed four concerns which were frequently mentioned by male respondents: (a) vasectomy makes men weak and less productive which they cannot afford being the main bread-earner of their families. Many women also felt the same way; (b) vasectomy demands rest for several days which again males cannot afford, particularly if they have to earn their living on a day-to-day basis; (c) women do not do hard work, they live in home and hence can take rest; and (d) tubectomy is easier than vasectomy and does not require much rest. Yet another important concern which was shared by majority of the males was failure of vasectomy and its social consequences for the couples. Their typical thinking is well reflected in the following quote verbatim:

"We know that vasectomy can fail and suspecting wife is wrong but all do not think in that way. How can you stop others saying that my wife had an affair with other man, that is why she became pregnant even after my accepting vasectomy".

15. Some of the men felt that the shift from vasectomy to tubectomy has taken place largely because of the side effects of vasectomy and availability of simpler and easy tubectomy method (laparoscopic). Majority (52 to 61 percent) of the men believed that tubectomy is easier, has less chances of complications and need shorter postoperative rest.

16. For many men when an easier and less complicated method like laparoscopy is available for women sterilization, there is no reason why should men undergo a more 'risky' operation. Clearly, the study is reflecting the impact of aggressive campaign and motivational efforts put in by the family welfare programme focussing females as their targets and the misinformation often the extension workers generated during their effort to recruit the 'cases' for meeting their family planning targets.

17. Not many men including male family planning workers felt that vasectomy could be made again a popular method. As one of the male community members puts it:

"It has now become a custom that only women undergo sterilization. Now if I adopt vasectomy, people will laugh at me."

18. In general, four suggestions for reintroducing vasectomy were made:

(a) provision of an attractive incentive; (b) aggressive educational campaign;

(c) detailed and focussed counselling of men explaining both advantages and disadvantages of the method; and (d) increased availability of operation facilities 
and organizing regular vasectomy camps. The last recommendation is particularly important. Though, theoretically, vasectomy is available and offered to prospective clients, in reality, its service is almost non-existent at rural PHCs or CHCs. Today, most of the doctors posted at PHCs have no skill and/or practical experience of conducting vasectomy.

19. Several reasons were identified for the low use of condom. They include: dislike for the method (39 percent); poor quality of condom/fear of its failure (22 percent); unawareness of the method (21 percent); non-availability in the villages (15 percent); loss of sexual enjoyment (13 percent); and storing/disposal problems (12 percent). Indepth case studies are required to assess how far these complaints are correct and to what extent failure of the condom is due to incorrect use of the method.

20. In India, where spacing is still an alien concept, the chances of increasing acceptability of condom use among men in face of their existing dislike for the method is doubtful. To ensure higher acceptability of condom, the main target group should be young couples. Selling of the concept of 'safe sex' and 'spacing as key to sexual enjoyment', perhaps would be more effective. Awareness about STD and AIDS among men and about the condom as a preventive measure could alter cultural bias against condoms both among men and women, and may increase the acceptability and use of the contraceptive.

21. Analysis of the men's awareness about the legal status of abortion and their attitude towards it revealed that less than one-fourth (22 percent) were aware that abortion is legal. 68 percent believed that MTP is illegal and undergoing abortion is a criminal offense. The study also revealed that two-thirds of the males were against MTP as 'it is a sin' or amount to 'killing of an unborn child'.

Further analysis shows a direct relationship between awareness of the legal status of abortion and approval of MTP. For instance, 35 percent men who were aware that MTP was legally approved abortion as compared to only 3 percent who believed that MTP is illegal. This indicates an urgent need of launching educational campaigns to make the community aware of the legal status of MTP. Such awareness could help in making community attitude favourable to MTP and thus facilitate women to seek help from recognized safe hygienic abortion services for MTP rather than approaching untrained illegal abortionists. 


\section{MALE INVOLVEMENT IN FAMILY PLANNING \\ - A KABP STUDY OF AGRA DISTRICT}

\section{Introduction}

Although concern of lack of male-involvement in family planning has been a topic of research and discussion since early eighties, during the last five years and particularly after the Cairo and Beijing Conferences, it has become an important issue for women advocates, researchers and many international agencies who are committed to reproductive health and gender equalities. The large number of articles on this subject (Davies, et al. 1987; Mason and Taj, 1987; Green, 1990; Spieler, 1991; Cleland, 1992; Ringheim, 1993; Bruce, 1994; Piotrow, et al. 1994; Schuler, et al. 1995; UNFPA, 1995; Piet-Pelon and Rob, 1996; Aguma, 1996; Khan, et al, 1997 a,b)) and growing number of conferences, research projects and debates are testimonies of the importance of the issue, both from the programmatic point of view as well as a process for bringing about a gender balance in men's and women's reproductive rights and responsibility.

A recent publication of UNFPA (1995) lists the following reasons for the growing importance of male-involvement initiatives in family planning:

-The advent of the AIDS epidemic has spurred intense interest in condom promotion;

- Men are more favourable to the general principle of family planning than has been assumed;

-Male support affects both the adoption and the correct use of female contraceptives;

-Male-involvement programs can be cost-effective if they are highly focussed and offer male contraceptive methods directly or by referral;

- Men's role in the abuse of reproductive rights and sexual violence directed towards female partners and relatives should no longer be ignored; and

-The international consensus reached at ICPD has created a momentum for action.

One major difference between the concern for increasing male participation in family planning till recently (late eighties) and now is the conceptual shift in the objectives itself. Earlier the main concern for increasing male participation in family planning was increasing contraceptive use and achieving demographic goals. In contrast, the Cairo declaration demands men's participation in family planning and reproductive health in terms of gender equality and fulfilling various reproductive responsibilities. 
It is argued that "men are partners in reproduction and sexuality and therefore it is logical that they equally share satisfying sexual lives and the burdens of preventing diseases and health complications" (Green, et al., 1995). This broadening of the concept of 'male-involvement' to 'male-responsibility' demands changes in the strategies of educational campaigns and motivational efforts also where men and women need to be educated and informed about gender equality, their reproductive rights and responsibilities and not only about the adoption of contraception.

Available studies show that in many developing countries males often dominate in taking important decisions in the family, including reproduction, family size and contraceptive use. Male-involvement not only helps in accepting a contraceptive, but also in its effective use and continuation. On the other hand, even if the wife wants to use contraceptive, she may not be able to use it or may be forced to discontinue the method, if the husband disapproves of contraception.

$\mathrm{H} u \mathrm{~s}$ b a n d - w i f e communication on contraception and their reproductive goals suggests an egalitarian relationship between husband and wife. There are several studies, mostly carried out in $60 \mathrm{~s}$ and $70 \mathrm{~s}$, revealing that couples who talk or discuss among themselves about the number of children they should have or the use of family planning, are more likely to use a contraceptive and achieve their reproductive goals than those who do not. Available studies on husband-wife communication also show that a very small proportion of couples discuss sexual matters or contraceptive use.

In India, the study of male's role in family planning is still a neglected area. However, historically, in the Indian family planning program, the contraceptive use pattern has undergone major changes during the last 30 years. From 1960 to 1977, males were the main acceptors of family planning (vasectomy and condom) and their proportion was always more than 50 per cent of the total family planning acceptors. However, as a consequence of the excesses during the emergency for promoting vasectomy, the program received a major set back. With the introduction of new technology like mini-lap and laparoscopic sterilization slowly the program orientation shifted towards women. 
Since 1977-78, tubectomy has dominated the family planning scene. Vasectomy which was once the most popular method now contributes less than 5 per cent of the total sterilization cases every year (Figure 1). Recently an attempt is being made by the program managers to again popularize vasectomy, but so far without much success.

There is an urgent need, on the one hand, to understand the level of knowledge and attitudes of males towards family planning and the extent they feel their responsibilities in family formation and reproductive health. On the other hand, a series of operations research needs to be undertaken to develop and test models on how to better involve males in family planning and to make them gender sensitive and more responsible for meeting their reproductive goals. The present study was undertaken as the first step towards developing an operations research for enhancing male-responsibility in family planning in Agra and Sitapur districts, the two OR districts in Uttar Pradesh where the Population Council is working closely with the district health authorities to improve the functioning of family welfare program.

\section{Objectives of the Study}

The objective of the study was to understand the knowledge, attitude, belief and practices of males towards reproduction and family planning. More specifically, the study addressed the following aspects:

1. What is the family size norm of males?

2. To what extent are they aware of various family planning methods and how far they support the use of contraceptives?

3. What is their level of contraceptive use and what are the reasons for preferring one contraceptive over the other?

4. What is their attitude towards decision making on issues related to reproduction and contraceptive use?

5. Wherever possible, to compare the men responses with those of women of the same area who were interviewed about three months before the present survey. 


\section{Data}

The study was carried out in three block PHC areas of Agra district, namely, Achhnera, Akola, and Fatehpur Sikri in which the Population Council is implementing various Operations Research (OR) projects. For selecting the villages and sample households, the same sampling procedure was adopted as in the case of UP Baseline Survey (for details see Agra, Population Council, 1995). A total of 21 villages were covered in male involvement study. The sample of 500 households was allocated to the selected villages in proportion to their population size. From each village, the required number of sample households was selected at random. From each selected household, all currently married males were interviewed. Out of the 490 households which were finally contacted, a total of 524 males were interviewed. However, after dropping seven incomplete cases, a complete data set was available for 517 males.

For comparison purposes, responses of 317 women who were selected from the same area under the UP Baseline Survey and were interviewed about 3 months before the current study have been used. The survey design and questionnaire used in the two surveys were almost identical except a few additional questions that were added in the male survey.

\section{Findings}

\section{Profile of the Respondents}

Altogether 517 currently married men were interviewed. The average age of the respondents was 34.2 years (S.D. $=8.8$ ) with about 60 per cent falling in the age group of 20-39 years. Two-thirds were married by the time they completed their 20th birthday (mean 19.9 years). On an average, they had 3 living children (mean 3.2, S.D.= 2.1). The proportion of males, however, having four and more living children was 42 per cent.

About 18 per cent in each category were either illiterate, had schooling up to primary class, or had education up to middle level. One-fourth had schooling upto matric, while the remaining 20 per cent had schooling beyond eleventh class. Professionally, about half (47 per cent) were cultivators, while about 15 per cent were unskilled construction workers. A small proportion was engaged in salaried jobs ( 7 per cent) or in business ( 7 per cent) or were working as skilled worker (see Table 1). 
Table 1: Socio-economic characteristics of the couple

\begin{tabular}{|c|c|c|}
\hline & Husband & Wife \\
\hline Present age (completed years) & & \\
\hline$<19$ & 1.0 & 10.4 \\
\hline $20-24$ & 13.2 & 23.7 \\
\hline $25-29$ & 22.4 & 21.1 \\
\hline $30-34$ & 18.2 & 18.0 \\
\hline 35-39 & 16.4 & 11.7 \\
\hline $40-44$ & 14.1 & 6.9 \\
\hline $45-49$ & 8.7 & 8.2 \\
\hline 50 or more & 6.0 & -- \\
\hline Mean & 34.16 & 30.44 \\
\hline SD & 8.85 & 8.34 \\
\hline Age at effective marriage (gauna) & & \\
\hline$<15$ & 7.7 & 25.2 \\
\hline 16 & 5.6 & 44.5 \\
\hline 17 & 6.4 & 10.8 \\
\hline 18 & 12.4 & 13.3 \\
\hline $19-20$ & 32.1 & 5.4 \\
\hline 21 or more & 35.8 & 2.5 \\
\hline Mean & 19.9 & 16.95 \\
\hline SD & 2.83 & 2.24 \\
\hline Marital status & & \\
\hline Married & 99.8 & 99.6 \\
\hline Divorced/separated & 0.2 & 0.4 \\
\hline Educational level & & \\
\hline Illiterate & 18.2 & 78.5 \\
\hline Upto primary (1-5) & 18.0 & 11.1 \\
\hline Upto middle (6-8) & 17.4 & 7.3 \\
\hline Upto high school (9-10) & 25.9 & 2.2 \\
\hline Above high school $(11+)$ & 20.5 & 0.9 \\
\hline Main occupation & & \\
\hline Service & 6.8 & 0.6 \\
\hline Business & 6.6 & 0.3 \\
\hline Skilled worker & 13.0 & 0.3 \\
\hline Professional & 1.5 & -- \\
\hline Agriculture labour & 6.4 & 0.3 \\
\hline Unskilled/construction worker & 14.7 & 3.5 \\
\hline Cultivator & 46.8 & 0.9 \\
\hline Housewife & -- & 92.2 \\
\hline Too old for job/disabled & 0.8 & 1.6 \\
\hline Unemployed & 2.9 & -- \\
\hline Others & 0.5 & 0.3 \\
\hline Total number of persons & 517 & 317 \\
\hline
\end{tabular}




\section{Access to Mass Media}

An analysis of exposure to mass media shows that about 90 per cent of the men had access to at least one mass media, i.e., newspaper, radio, television or cinema. The remaining 10 per cent were not exposed to any media (Figure 2). The proportion of men having regular exposure ( 3 or more times a week) varied by type of media - 19 per cent to newspaper, 22 per cent to radio and 18 per cent to television. About 22 per cent of the males reported viewing cinema at least once in two months.

A comparison of these findings with the media exposure of women living in the same area showed a wide gap. According to the study, 66 per cent of the women had no access to any mass media and the proportion of women having regular access to newspaper, radio and television was negligible (Table 2 ).

Table 2: Access to media

\begin{tabular}{|l|r|r|r|r|r|r|}
\hline & \multicolumn{2}{|c|}{ Newspaper } & \multicolumn{2}{c}{ Radio } & \multicolumn{2}{c|}{ Television } \\
\cline { 2 - 7 } & Men & Women & Men & Women & Men & Women \\
\hline Never & 37 & 96 & 32 & 77 & 48 & 82 \\
Rarely & 35 & 3 & 36 & 13 & 25 & 8 \\
Sometime & 9 & 1 & 10 & 5 & 9 & 3 \\
Regularly & 19 & - & 22 & 5 & 18 & 7 \\
\hline
\end{tabular}

\section{Ideal Family Size Norm}

Table 3 presents the perceived ideal family size of men and women which, according to them, a couple should inspire to achieve. The analysis reveals that majority of the males favoured a three (53 per cent) or four or more child ( 25 per cent) family. While it is important to underline that still, a substantial proportion (31 per cent) of males favoured large families (4 or more children), it is also encouraging to note that at least about onesixth (16 per cent) of the men feel that even one ( 4 per cent) or two children (12 per cent) are adequate. 
Analysis of the women's response to the same question revealed almost the same pattern of perceived ideal family size. In the case of both men and women, the mean of ideal family size was estimated to be 3.1 (Table 3). It is almost the same as reported in NFHS (3.0 in 1992) and in the Third All India Family Planning Survey (3.1 in 1989). It also shows that during the last 6-7 years no change has taken place in perceived ideal family size.

Table 3: Ideal number of children

\begin{tabular}{|l|r|r|r|r|r|r|}
\hline \multirow{2}{*}{ Sex of respondents } & \multicolumn{1}{|c|}{ Percentage } \\
\cline { 2 - 8 } & $\mathbf{2}$ & $\mathbf{3}$ & $\mathbf{4}$ & $\mathbf{5 +}$ & Mean & Total N \\
\hline Men & 16 & 53 & 25 & 6 & $3.2 \pm 0.8$ & 517 \\
\hline Women & 22 & 49 & 23 & 6 & $3.1 \pm 0.9$ & 317 \\
\hline
\end{tabular}

Further analysis
by ideal sex
composition of
children revealed that
both among males
and females, a
majority wanted 2 or more sons. Only about 26 per cent of the men and 31 per cent of the women felt that it is ideal to have one son. On the other hand, majority of both men and women $(66$ per cent men and 69 per cent women) wanted at

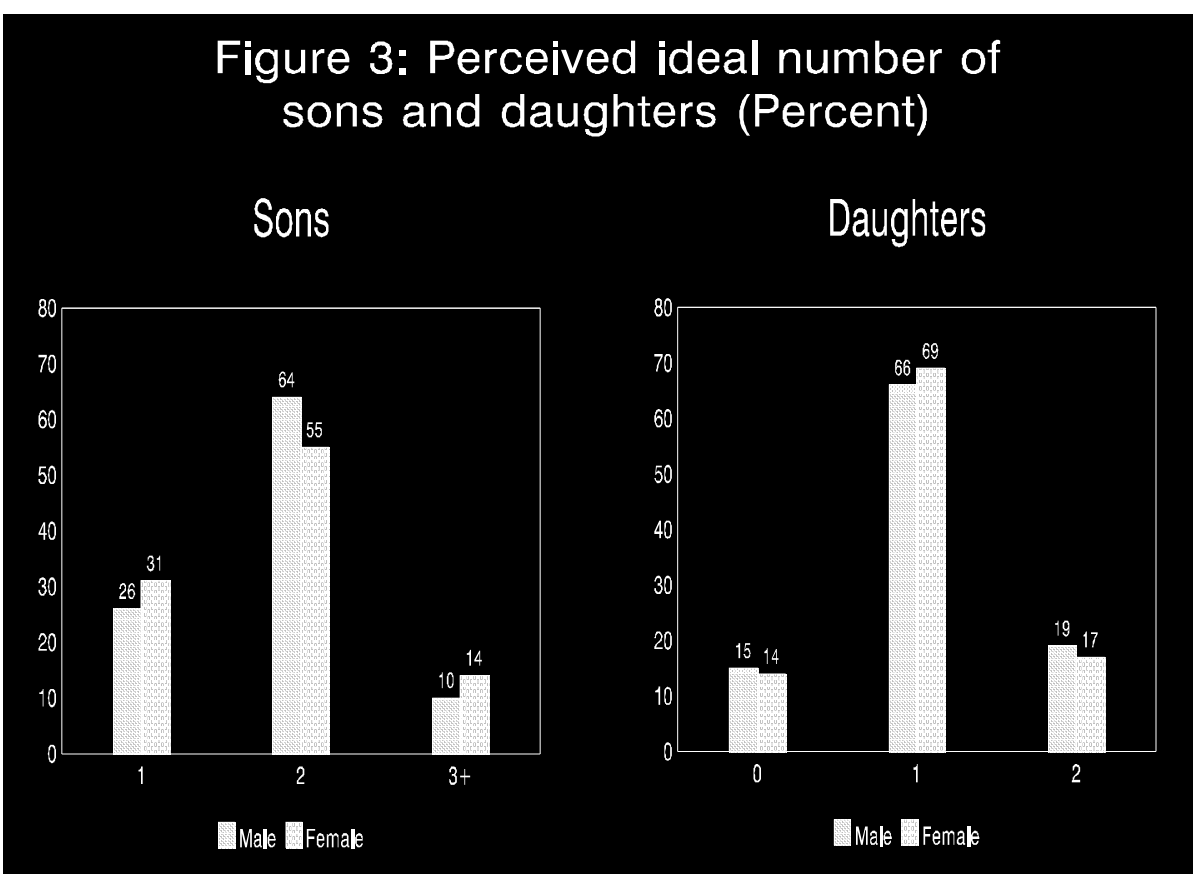
least one daughter. It is important to note that about 14 to 15 per cent of men and women did not want even one daughter. This suggests a shift in the ideal family size norm as even 15 years ago (ORG, 1982) almost all parents wanted at least one daughter. They believed that without doing 'Kanyadaan' (gifting daughter through marriage) they would not get Moksha after death. A similar comparison with proportion of men or women satisfied with only one son (32 per cent in 1989) shows little change in the norm (ORG, 1990). In other words, when an increasing number of couples are less interested in having any daughter, the son bias and desire for at least two sons is fairly stable overtime. 


\section{Attitude of Respondents about Various Reproductive Decision Making Processes}

\section{Perceived Ideal Age at Marriage}

The study reveals that about one-third of the male respondents were of the opinion that girls should be married as early as possible and certainly by the time they complete their 17th year (Table 4). Another, 38 per cent recommended 18 years while the rest favoured 19 years or more as an appropriate age for marrying girls. A comparison of these figures with the answers of women respondents showed that a larger proportion of the women (46 per cent) than males favoured early marriage of girls, i.e., 17 years or more. At the same time, it is also important to note that only one-fifth of the men as against one-third of the women favoured delaying marriage of girls till 20 years or more.

Table 4: Perception about time when a girl should get married

\begin{tabular}{|l|r|r|}
\hline & Husband & Percentage \\
\hline Age when a girl should be married & & Wife \\
$<16$ years & 15 & 24 \\
16 years & 11 & 16 \\
17 years & 9 & 6 \\
18 years & 38 & 19 \\
19 years & 6 & 2 \\
20 or older & 21 & 34 \\
Mean $\pm S D$ & & \\
\hline
\end{tabular}

Further probing revealed that only 60 per cent of the men were correctly aware of the age at which a girl could be legally married (18 years). A still smaller proportion (45 per cent) were aware of the legal age at marriage for boys (21 years). The proportion of women who were correctly aware of these legal ages was only 28 and 13 per cent respectively (Figure 4).

\section{H u s b a n d - W i f e Communication}

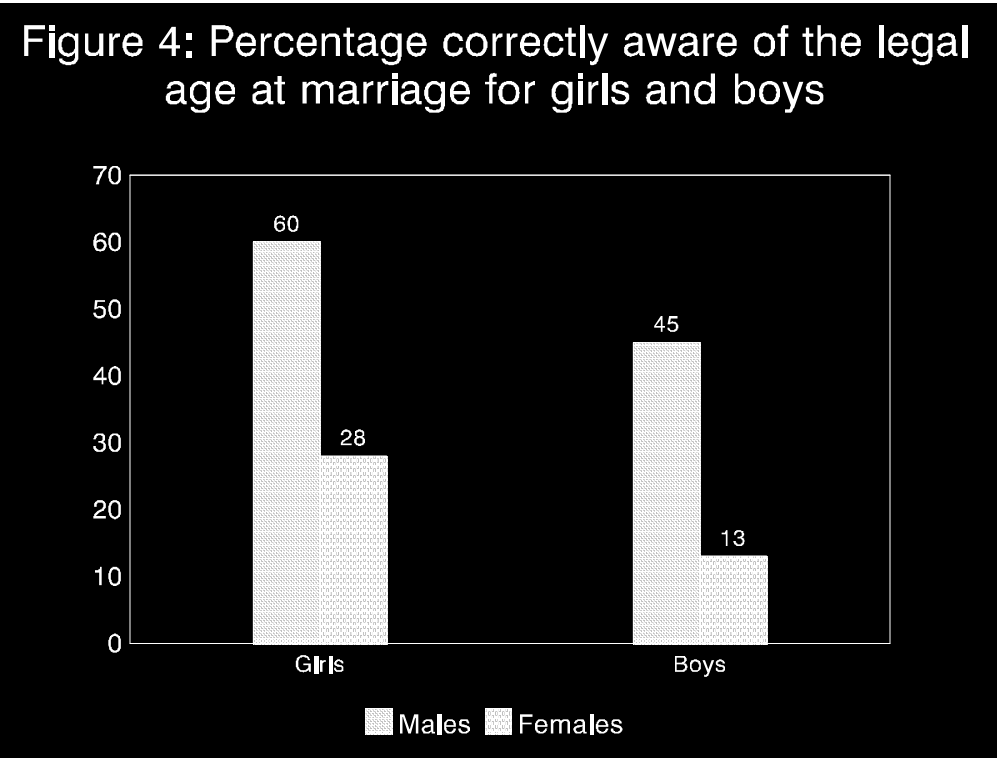

The low status of women in the

family influences their life in different ways, including their right to control sexuality and reproductive goals. Most of the available studies show little husband-wife communication on topics related to reproductive intentions, contraception or planning of pregnancies (Khan, 1979; ORG, 1990, NFHS, 1994; BSUP, 1995; CORT, 1996)). In most cases, such discussion takes place only after the birth of two or three children and is mostly initiated 
by husbands. Many women consider discussions on such topics as a 'shameful act' (Khan, 1997). In the present study, a series of questions were asked to all male respondents to assess their attitude towards husband-wife communication and the role and rights of spouses in deciding reproductive goals.

The study reveals that only 56 per cent of the men had any discussion with their wives about the number of children they should have. More than half (58 percent) of the men who reported such discussion said that they discussed it immediately after marriage and in majority of the cases (71 per cent) it was initiated by them (Table 5).

A comparison of these findings with the responses of women reveals that though a larger proportion (71 per cent) of the women reported husband-wife communication, a majority (64 per cent) reported such discussion after their second or third child (Table 5). The discrepancy between men and women's response on the husband-wife communication can't be explained from the present data set. A small qualitative research to understand the dynamic of husband-wife communication and the reported discrepancy would be useful.

Table 5: Husband-wife communication on reproductive matters

\begin{tabular}{|c|c|c|}
\hline \multirow{3}{*}{ Husband-wife communication } & \multicolumn{2}{|c|}{ Percentage } \\
\hline & RespoI & \\
\hline & $\begin{array}{c}\text { Men } \\
N=517\end{array}$ & $\begin{array}{r}\text { Women } \\
N=317\end{array}$ \\
\hline$\%$ reporting husband-wife communication & 56 & 71 \\
\hline $\begin{array}{l}\text { Time when first discussed? } \\
\text { Immediately after marriage } \\
\text { After 1st child } \\
\text { After } 2 \text { nd child } \\
\text { After 3rd child } \\
\end{array}$ & $\begin{array}{l}58 \\
10 \\
18 \\
14 \\
\end{array}$ & $\begin{array}{l}17 \\
19 \\
24 \\
40\end{array}$ \\
\hline $\begin{array}{l}\text { Person who initiated the discussion? } \\
\text { Husband } \\
\text { Wife } \\
\text { Do not remember }\end{array}$ & $\begin{array}{r}71 \\
9 \\
20\end{array}$ & $\begin{array}{r}90 \\
5 \\
5\end{array}$ \\
\hline
\end{tabular}

The men who had reported no communication with their wives on reproductive goals or contraception or had discussed these issues only after having 2 or more children were further probed about what discourages spouses from discussing their reproductive goals and intentions. Their answers are presented in Table 6. 
Table 6: Perception of men on what discourages spouses from discussing contraception and number of children at an early stage of married life*

\begin{tabular}{|l|r|}
\hline Response & Percentage \\
\hline Shyness/newly married couples are unknown to each other & 34 \\
Due to illiteracy, no understanding & 20 \\
Did not think about 'these things'. It is natural process & 24 \\
This is unnecessary talk, do not help anyway & 22 \\
One must have 2-3 children before thinking about these issues & 12 \\
Women cannot give advice on these aspects. What to talk with them? & 7 \\
As children are an asset, nobody wants to talk how to limit them & 3 \\
Can't say & 8 \\
\hline Total N & 351 \\
\hline
\end{tabular}

According to their response--shyness (34 per cent), illiteracy (20 per cent), never occurred to them (24 per cent) and perception that these discussions are useless and do not help in anyway-- were the main reasons why spouses do not take initiative at an early stage of married life to discuss their reproductive goals. Interestingly, a small proportion ( 7 per cent) mentioned that women cannot give any advice on such matters, so why talk

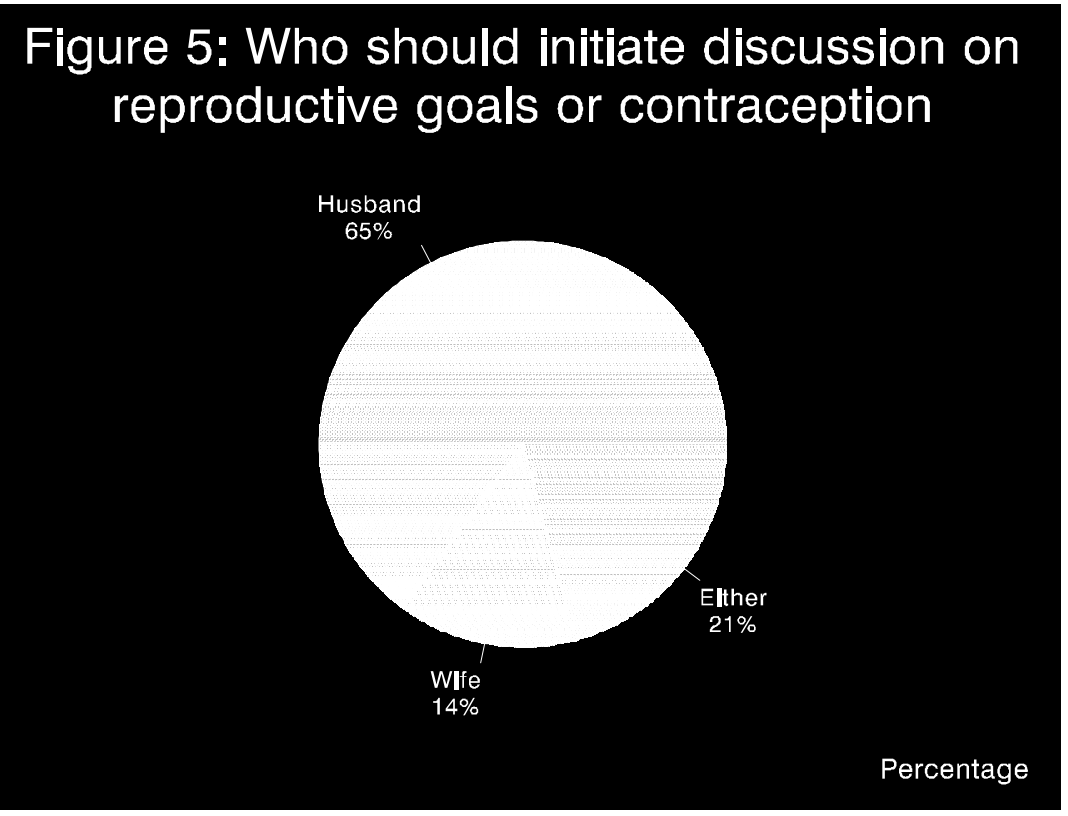
with them. This perhaps reflects the typical thinking of men that decisions on reproductive goals and contraception is a male's domain and women do not have any role in such matters. To some extent, this observation is supported by the fact that majority (65 per cent) of the male respondents were of the opinion that it is the husband's responsibility to initiate discussion on reproductive intentions or contraception, and that women should wait for husband's initiative (Figure 5). 


\section{Decision Making in Family Formation}

To further probe their attitude towards the decision-making process in reproductive behaviour, each male respondent was asked, how they would react if their wives, soon after marriage, take the initiative and express their reproductive intentions (Table 7).

Table 7: Perceived reaction of males, if their wives initiated discussion on their reproductive intentions soon after marriage

\begin{tabular}{|l|r|r|r|}
\hline \multirow{2}{*}{ If wife initiates discussion on } & \multicolumn{3}{|c|}{ Men's reaction } \\
\cline { 2 - 4 } & Favourabl & Neutral & Adverse \\
\hline Number of total children they should have & 65 & 7 & 28 \\
When should they have their first child & 65 & 7 & 28 \\
Whether they should use contraceptive & 60 & 9 & 31 \\
Which method they should use & 57 & 9 & 34 \\
\hline
\end{tabular}

As the table shows around two-third of the men felt that their reaction would be favourable. Interestingly, however, a little less than one-third felt that their reaction would be adverse as they did not believe that a woman should take initiative on these matters. To probe further as to who in their family has the right to take decisions on various aspects of reproductive behaviour, each of them were asked six questions as listed in Table 8 with their responses.

Table 8: Who decides in the family about reproductive behaviour

\begin{tabular}{|l|r|r|r|r|}
\hline Who decides about & $\begin{array}{r}\text { Husban } \\
\text { d alone }\end{array}$ & $\begin{array}{r}\text { Wife } \\
\text { alone }\end{array}$ & $\begin{array}{r}\text { Both } \\
\text { together }\end{array}$ & Nobody \\
\hline Number of children a couple should have & 52 & 1 & 41 & 6 \\
Number of son(s) a couple should have & 45 & 1 & 45 & 9 \\
Planning of 1st and subsequent pregnancy & 38 & 9 & 49 & 4 \\
Abortion of unwanted pregnancy & 40 & 6 & 52 & 2 \\
When to adopt family planning & 48 & 2 & 47 & 3 \\
Which method of family planning & 49 & 3 & 45 & 3 \\
\hline
\end{tabular}

The analysis reveals that on all the aspects of reproductive processes -- number of children, timing of pregnancy, contraception, choice of contraceptive method and abortion of unwanted pregnancy--decisions would be taken exclusively by the husband (38 per cent to 52 per cent) or jointly by husband and wife ( 41 per cent to 52 per cent). Women have little right to take independent decisions on their sexuality or reproductive goals. Except in the case of timing of pregnancy or abortion of unwanted pregnancy when 9 and 6 per cent of the men respectively felt that women could take independent decision, in all other aspects of reproduction, less than 2 per cent of the men were of the view that women could take independent decisions. 
Husband's (men's) dominance in decision-making is not only confined to reproductive behaviour but also in health care. Probing on who decides when or which doctor to be consulted if a child in the family is sick, reveals that in half of the cases it is the husband, in 21 per cent cases it is decided jointly by husband and wife, while in another 18 per cent of the cases it depends on the situation (Figure 6). It is striking that not even 1 per cent of the men said that women could take independent decisions about the timing of medical consultation or source of treatment.

Further probing on who generally is responsible for taking a sick child (less than 3 years old) to the doctor revealed that no fixed pattern is followed. One-third (35 per cent) of the respondents felt that both father and mother are jointly responsible for that, while, 17 per cent felt that mostly it is the father who takes the sick child to clinic. About 29 per cent felt that it depends on the situation and availability of the person at home. Only 6 per cent felt that it was mother's responsibility to take the child to a doctor.

The above analysis, thus, clearly indicates that men are the key decision makers on all aspects of reproduction, family formation and health seeking behaviour. Apparently, most of them also do not have any wish to abdicate the role. Women neither have control of their sexuality nor on their reproductive goals. Nevertheless, about half of the men are ready to take joint decision with their wives. Educational and advocacy programs should try to act upon these observations and strengthen intentions of the men who expressed readiness to share decision making power with their wives. Any educational program for influencing reproductive intentions of couples or promotion of contraception which neglect men may not have the desired impact.

Similarly, investments on increasing availability and utilization of the reproductive health services may not yield desired results unless men are educated and informed about the reproductive health problems and STD, as well as the long term repercussions of the diseases on the women's health and for the family as a whole. 


\section{Family Planning}

\section{Knowledge, Attitude and Practice of Family Planning}

As expected, awareness of family planning methods is universal and, on an average, every male respondent was aware of 3 or more modern methods. To test their knowledge, a number of questions were asked about each method such as who (sex) uses it, and how is it used or performed. Based on their answers, they were classified into those who had full, partial and wrong knowledge about the methods. The analysis revealed that less than half of the men had correct knowledge of vasectomy ( 46 per cent), tubectomy ( 45 per cent) and oral pills (41 per cent). Very small proportion of the men had correct knowledge of IUD (18 per cent), injectable ( 1 per cent), and safe period (29 per cent). Most men and women were aware of condoms and how to use them correctly.

Table 9: Awareness and correct knowledge of men and women about different family planning methods

\begin{tabular}{|l|r|r|r|r|}
\hline \multirow{2}{*}{ FP Methods } & \multicolumn{2}{|c|}{ Awareness } & \multicolumn{2}{c|}{ Correct knowledge } \\
\cline { 2 - 5 } & Men & Women & Men & Women \\
\hline Vasectomy & 91 & 93 & 46 & 26 \\
Tubectomy & 91 & 97 & 45 & 82 \\
IUD & 44 & 72 & 18 & 35 \\
Oral Pills & 72 & 86 & 41 & 29 \\
Condom & 89 & 91 & 77 & 76 \\
Injection & 6 & 32 & 1 & 0 \\
Withdrawal & 11 & 49 & 9 & 43 \\
Safe period & 42 & 60 & 29 & 46 \\
\hline Total & 517 & 317 & 517 & 317 \\
\hline
\end{tabular}

A comparison with the women's response from the same area shows that awareness of different family planning methods was slightly higher among women, particularly for IUD (72 per cent), injectable (32 per cent) and safe period (60 per cent). Surprisingly, even withdrawal was mentioned more by the women than the men. Similarly, somewhat larger proportion of women had correct knowledge of contraceptive methods, particularly for tubectomy, IUD and safe period. In the case of pills and vasectomy, a larger proportion of the men had correct knowledge about the methods than the women. It is important to note that for injectable contraception (DMPA) though 32 per cent were aware of the method, not a single woman had detailed or correct knowledge about it. This is perhaps largely because DMPA has yet not been included in the public programme and, thus, it is neither available through public sources nor information is imparted through IEC channels.

The main sources of information about family planning methods for the men were reported to be friends ( 65 per cent), mass media (47 per cent) and health workers (11 per cent). Among other sources, 'wife' was mentioned by about 6 per cent of the men. 


\section{Attitude Towards Family Planning}

Most (85 per cent) of the males were in favour of family planning. About 11 per cent were indecisive, while 4 per cent disapproved of contraception. Further probing, however, revealed that slightly more than half (55 per cent) of those who approved of contraception, favoured its use only after having two or more children (Figure 7). The remaining 45 per cent, however, approved use of family planning methods immediately after marriage ( 9 per cent) or any time when the couple wants (21 per cent).

Few (4 per cent) who disapproved of family planning felt that contraception was against religion and morally bad for society, or believed that existing methods were harmful for the health.

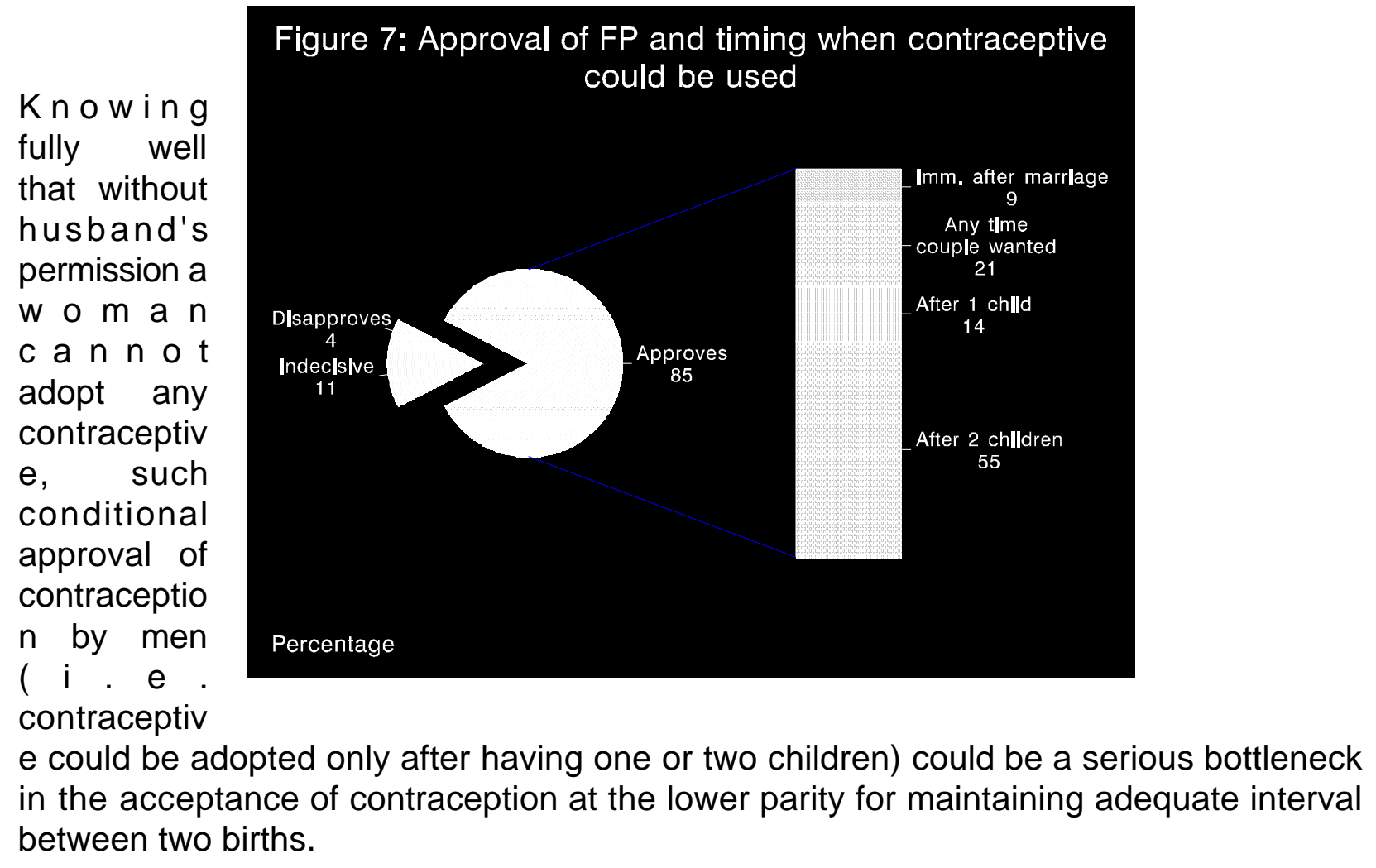

\section{Current Use of Contraceptives}

Current use of family planning in the study area as reported by men and women is given in Table 10. 
Table 10: Current use of contraceptive

\begin{tabular}{|l|r|r|}
\hline Methods & Men & Women \\
\hline Any method & 43.4 & 30.5 \\
Any modern method & 33.5 & 20.4 \\
Vasectomy & 2.9 & 0.5 \\
Tubectomy & 17.0 & 14.2 \\
IUD & 0.8 & 0.5 \\
Pill & 3.1 & 0.9 \\
Condom & 9.7 & 4.3 \\
Traditional & 9.9 & 10.1 \\
\hline Share of male methods & & \\
Taking modern method only & 37.6 & 22.7 \\
Taking all methods & 52.2 & 48.4 \\
\hline
\end{tabular}

According to male respondents, about 34 per cent of them were using one or the other modern contraceptive. Apart from them, another about 10 per cent reported use of traditional methods, mainly `safe period'. Sterilization (20 per cent), mainly tubectomy (17 per cent), was the most popular method followed by condom (10 per cent). Use of IUD and oral pills was mentioned by only 1 and 3 per cent respectively. Share of modern male methods (i.e. proportion of males using vasectomy and condom) was only 37.6. However, it increases 52 per cent if use of all the methods including traditional one (safe period and withdrawal) are included in calculation.

A comparison of these results with the contraceptive use pattern reported by women of the same area reveals several interesting findings. For instance, a significantly higher percentage of contraceptive use was reported by men (34 per cent) than women respondents (20 per cent) -- a difference of about 14 per cent points. This difference was largely contributed by higher reported use of condom (5.4 per cent points), vasectomy (2.4 per cent points), tubectomy ( 3.2 per cent points), and pills (2.2 per cent points) by the male respondents (Table 10). While there are several studies (Khan, 1979; Mitra, 1985) which indicate that women tend to under-report use of male methods (condom, vasectomy and withdrawal), reasons for under- reporting of use of female methods by women is not clear, and needs further investigation.

It is also interesting to note that as long as only modern contraceptive methods are considered, share of male methods remained significantly low - only 38 and 23 percent as reported by the men and women respondents respectively. However, in both the cases, the proportion increases to about 50 percent, once all the methods including withdrawal and safe-period are considered. This indicates that overall participation of men in contraception use was not as poor as generally believed.

\section{Purpose of Contraception and Method Used}

Probing on whether men were using contraceptive to limit childbearing or delay birth of next child revealed that most of them (79 per cent) were using family planning methods to limit childbearing. Only about 21 per cent were spacers. A breakup of the limiters by type of method used reveals that while 58 per cent had adopted terminal methods, 42 per cent were depending on non-terminal methods, largely condom and pills, for limiting 
childbearing (Figure 8).

Further probing revealed that the initiative to adopt family planning was mostly taken by the husbands ( 67 per cent). In 12 per cent of the cases contraceptive was adopted on the advice of the doctor while in only 11 per cent of the cases initiative for contraception had come from the wife or some other significant member in the household (10 per cent).

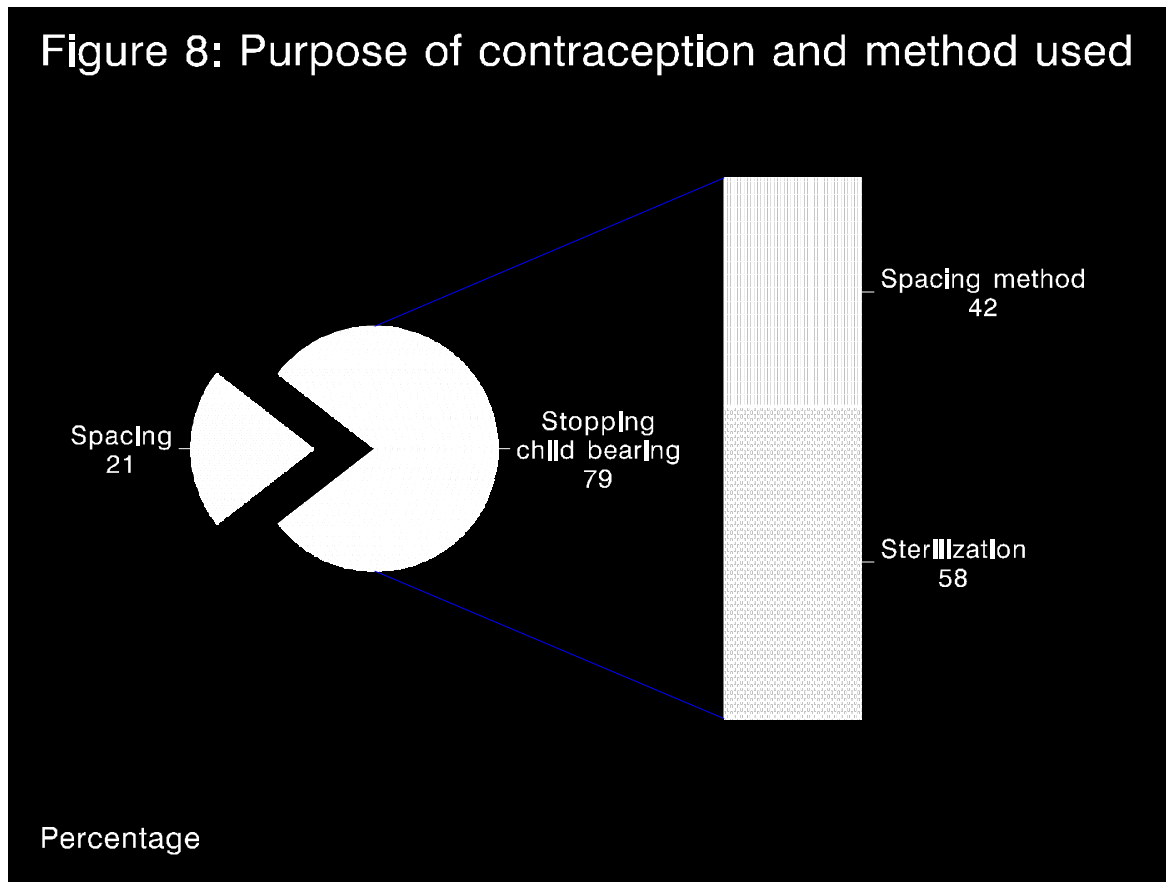

\section{Past Use}

91 males (18 per cent) were currently not using any family planning method, but had used it in the past. Of these, 70 per cent had used modern contraceptives, mainly condom (55 per cent) or pills (13 per cent). The remaining 30 per cent had depended on traditional methods, mainly safe period. About 30 per cent of the total past users (91 males) discontinued the method within 6 months, while the remaining used it for a longer period (7-24 months). The main reasons for the discontinuation of the methods included: desire for another child (62 per cent), lack of satisfaction (from condom) (15 per cent), and for 8 per cent it was lack of privacy in use (stocking, using and disposing of the method). 


\section{Unmet Need of Family Planning}

Unmet need is defined as the percentage of non-pregnant eligible women (currently married and sexually active women) who do not desire to have any more children or want their next child after two or more years; but are not practising any family planning method to protect themselves from unwanted pregnancies. On the one hand, it reflects the existing demand for family planning services while on the other, it also reveals the inability of the family planning delivery system to reach its potential clients. The NFHS

\section{Figure 9: Level of unmet need}

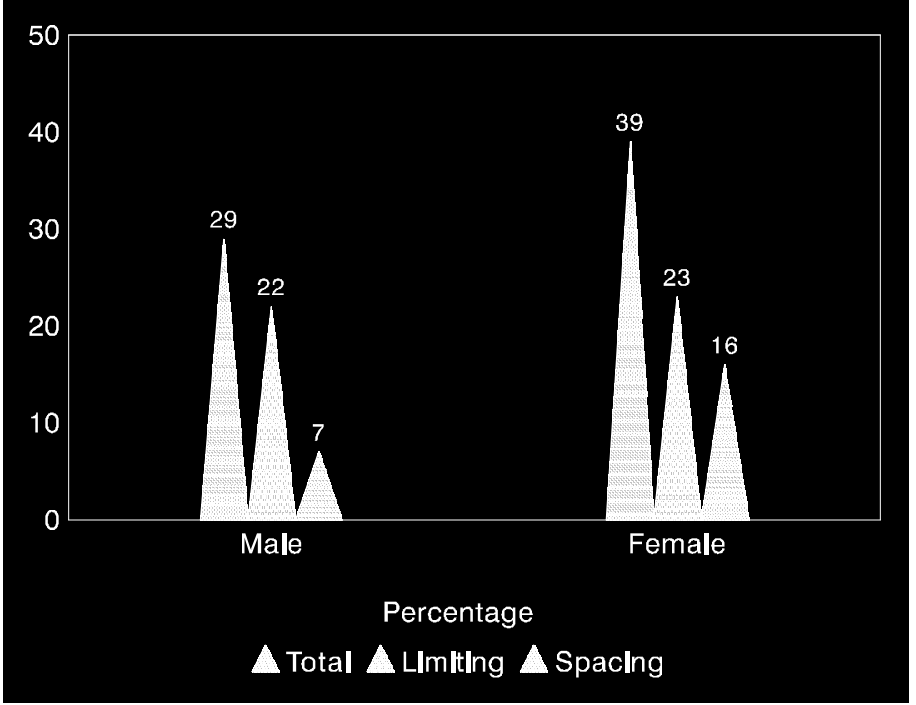
1994 estimated 30 per cent unmet need in Uttar Pradesh, whereas the UP Baseline Survey shows a variation in the level of unmet need between 23 per cent and 46 per cent. For Agra district the unmet need, as estimated by the UP Baseline Survey, was 36 per cent.

According to the men's response, the total unmet need was estimated to be around 29 per cent -- 22 per cent for limiting and 7 per cent for spacing (Figure 9). On the other hand, the unmet need as stated by women, was about 39 per cent -- 23 per cent for limiting and 16 per cent for spacing. The difference of 10 per cent points in total unmet need as stated by the men and women is perhaps largely because of the under-reporting of unmet need for spacing by the men.

This difference could be because husbands (men) who hold an opinion of the optimum family size might not be concerned with spacing between births. However, women who have to bear the burden of childbearing and rearing, wanted to delay the next child but could not use any method either because of the fear of side effects or because their husbands were not cooperative. Alternatively, this differential could be also because of the difference in reporting of contraceptive use by the men and women respondents. As we saw in the previous section, 34 percent of the men as compared to 20 percent of the women had reported use of contraceptive. More in-depth studies are required to understand these differences in the level of unmet need by gender.

\section{Why Males Prefer Tubectomy over Vasectomy?}

A probing on why males prefer their wives to undergo sterilization instead of accepting vasectomy themselves, which is medically a simpler and safe method, revealed major misconception about the methods as well as about woman's workload within family boundaries. As Table 11 shows, the men repeatedly underlined the following points: 
- Vasectomy makes men weak and less productive which being the main breadearner of their families, they cannot afford.

- Vasectomy demands rest which males again cannot afford as they have to work outside and earn a living on day-to-day basis.

- Women do not have to work hard, they live in the home and therefore can take rest.

- Tubectomy is easier than vasectomy and does not require much rest.

Table 11: Reasons why tubectomy is preferred over vasectomy

\begin{tabular}{|l|r|}
\hline \multicolumn{1}{|c|}{ Reasons } & Percentage \\
\hline Being earning hand, cannot take rest/male has to go & 13 \\
out for work while wife remains in home & \\
Causes kamjori/weakness & 48 \\
Reduces work output & 10 \\
Fear of side effects/impotency & 16 \\
Who will earn for family if males are bed-ridden & 6 \\
Fear of failure/cause embarrassment in community/ & 17 \\
gives a bad name to women & \\
Females themselves want to undergo sterilization/ & 8 \\
No trouble if females undergo sterilization/ & 10 \\
easier, less side effect, no social embarrassment & 3 \\
Men are self-centered/do not consider women as part of family & 9 \\
Others* & 4 \\
DK & 517 \\
\hline Total N & \\
\hline * Unawareness, people will laugh if vasectomized, female sterilization has become custom.
\end{tabular}

Yet another important reason which is shared by majority of the men, although in the actual interview it was mentioned by only about 17 per cent of the men, is vasectomy failure and its subsequent social consequences for the couples. In majority of such cases, the woman is suspected of infidelity. Even those men who believed that generally the blame of infidelity is wrong, during their interview, said:

"We know that vasectomy can fail and suspecting wife is wrong but all do not think in that way. How can you stop others saying that my wife had an affair with other man, that is why she became pregnant even after my accepting vasectomy."

In fact, when asked why couples have shifted from vasectomy to tubectomy, about 22 per cent of the men mentioned failure of the method and its adverse social consequence for the family as the cause of changes in the contraceptive use pattern in the country (Table 12). These perceptions are strongly held both by men and women and as a result, often (8 per cent), women themselves offer to undergo sterilization. As some of 
the women who were informally contacted during the field work commented:

"What will happen to our family if after operation he cannot work or become weak" (woman informant).

"If children die after wife's operation, he can marry another woman and produce son. If he gets operated the family will never get a son" (woman informant).

"Instead of taking risk for family and consequences of embarrassment if vasectomy fails, women prefer to undergo sterilization themselves" (woman informant).

Table 12: Reasons for shift from vasectomy to tubectomy

\begin{tabular}{|l|c|}
\hline Reasons & Percentage \\
\hline Failure of vasectomy caused embarrassment for women/ & 21 \\
family tension/fear of failure & 23 \\
Fear of side effects & 16 \\
Men have to work hard/trouble in doing hard work because of & 7 \\
kamjori (weakness) & 13 \\
Reduces work output & 10 \\
Men have to go out side for work/cannot take rest while women & 4 \\
stay at home & 7 \\
Earlier vasectomy was forced upon men & 3 \\
Women themselves want to undergo sterilization & 8 \\
Sterilization of women is easier and safer & \\
Now less emphasis and no facility for male sterilization now only women's & 6 \\
sterilization camps are organized & \\
To save himself from pain, he asks wife to undergo operation/women & \\
cannot say no/no benefits for men & \\
Do not know & \\
\hline Total N & \\
\hline
\end{tabular}

It is important, however, to point out that many women opt for the operation because they know that their husbands will not use any method and thus, they would continue to face the consequence of unwanted pregnancies. As one woman commented: 
"My husband himself did not want to use any method but after my fourth child, he also did not want any more child. When he suggested me that I should get sterilized, I readily agreed as I knew that this is the only way I could save myself from more pregnancies."

Table 13: Comparison of males' attitude towards vasectomy and tubectomy

\begin{tabular}{|l|r|r|r|r|}
\hline $\begin{array}{l}\text { Between vasectomy and tubectomy } \\
\text { which method }\end{array}$ & Vasectomy & Tubectomy & Both & Do not know \\
\hline Is easy to perform & 17 & 61 & 9 & 13 \\
Has less chance of post-operative & & & & \\
complications & 18 & 58 & 9 & 15 \\
Has fewer side effects & 19 & 56 & 10 & 15 \\
Needs less rest & 22 & 52 & 12 & 14 \\
\hline
\end{tabular}

Further probing, however, also revealed that most of the men believed that between vasectomy and tubectomy, tubectomy is easier to perform (61 per cent), has less chance of post-operative complications (58 per cent) and side effects (56 per cent) and required less rest.

Reasons for preferring tubectomy over vasectomy as given by the men who had reported tubectomy of their wives, followed almost the same pattern (Table 14).

Table 14: Reasons for preferring tubectomy over vasectomy as given by sterilized couples

\begin{tabular}{|l|r|}
\hline Answers * & $\begin{array}{r}\text { Percentag } \\
\text { e }\end{array}$ \\
\hline Men have to work hard and earn money. Vasectomy could make them weak & 63 \\
Women stay at home thus can take rest, men can't stop working or earning money & 52 \\
Vasectomy may fail. It causes major family tension. Wife's character is suspected & 8 \\
Wife herself wanted to get sterilized & 18 \\
Fear of operation & 5 \\
Other family members (in-laws) decided & 4 \\
Others & 7 \\
\hline Total N & 88 \\
\hline
\end{tabular}

* Percentage adds to more than 100 because of multiple response.

Informal discussions with several PHC staff (Male MPW) about the reasons why men are not coming forward for vasectomy revealed that with the arrival of laparoscopy, in motivational efforts the workers over-emphasized simplicity of the laparoscopy method by saying that after an operation women can attend the household chores on the same day. Earlier, when tubectomy was relatively major operation as compared with vasectomy and required hospitalization and rest of women for a few days (at least for 6 to 8 days), men offered themselves for vasectomy. However, once laparoscopy was projected as a 
method easier than vasectomy and more effective, males asked the women to get sterilized. Over time availability of vasectomy services has also reduced significantly today, hardly any doctor posted at PHC has practice of doing vasectomy operation.

Suggestions from the respondents on possible ways to promote vasectomy among men could be broadly classified into the following interventions (Figure 10).

- Provision of an attractive incentive.

- Aggressive educational campaign focussing particularly to men.

- Detailed and focussed counselling of men explaining both the advantages and disadvantages of the methods.

- Increased availability of operation facilities and regular vasectomy camps.

While the first suggestion needs further Figure 10 Suggestions to popularise vasectomy debate, the remaining three suggestions are important and need immediate attention of the policy makers. It is important to point out that today hardly any doctor posted at the PHC has the practical experience of conducting vasectomy and during the last five years, few camps have been organized for conducting vasectomy. On the other hand, at least at

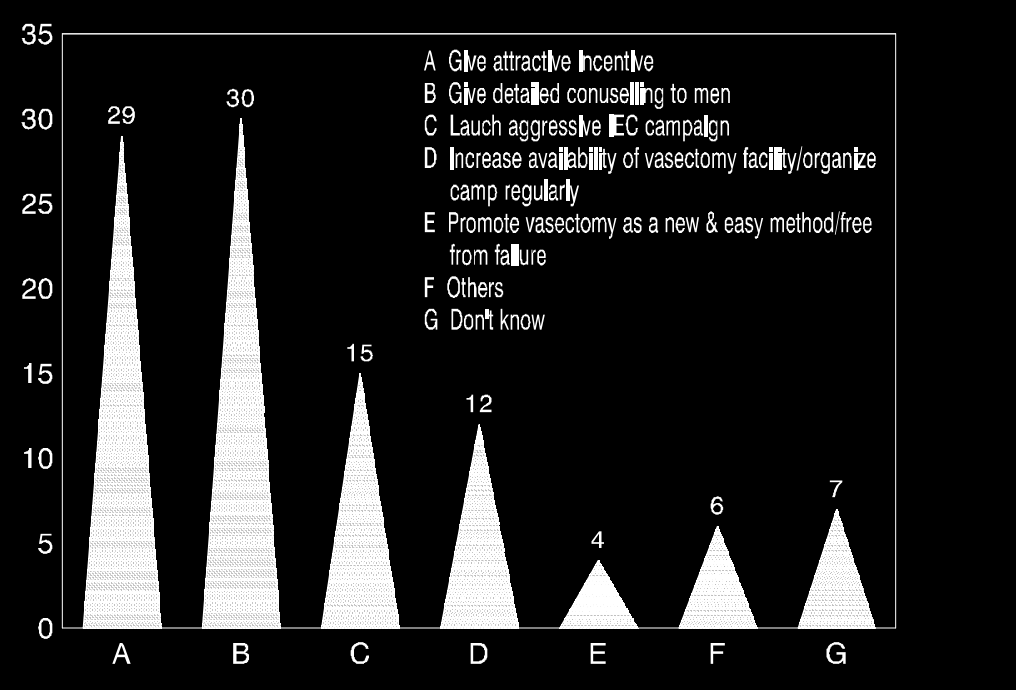
each block PHC level almost every week, a tubectomy camp is organized during October-March period of the year. For all practical purposes, in rural areas facility for vasectomy is presently not available. Nonavailability of vasectomy facilities in villages and sustained program emphasis on tubectomy during the last 20 years, has created an impression among the men that the responsibility of family planning is that of women and their thinking is well reflected in the following comment by a male informant.

"It has now become a custom that only women undergo sterilization. Now, if I adopt vasectomy, people will laugh at me." 


\section{Reasons Why Condom Use is Low?}

A detailed probing on why despite of the easy availability of condoms for such a long period, often men do not use them, the respondents could identify several reasons (Figure 11). It included: (a) disliking of the method (looks dirty, inconvenient to use, 39 per cent), (b) fear of failure/poor quality of condom (22 per cent), (c) unawareness (21 per cent), (d) lack of availability in villages (15 per cent), (e) loss of sexual

\section{Figure 11: Reasons why condoms are not used}

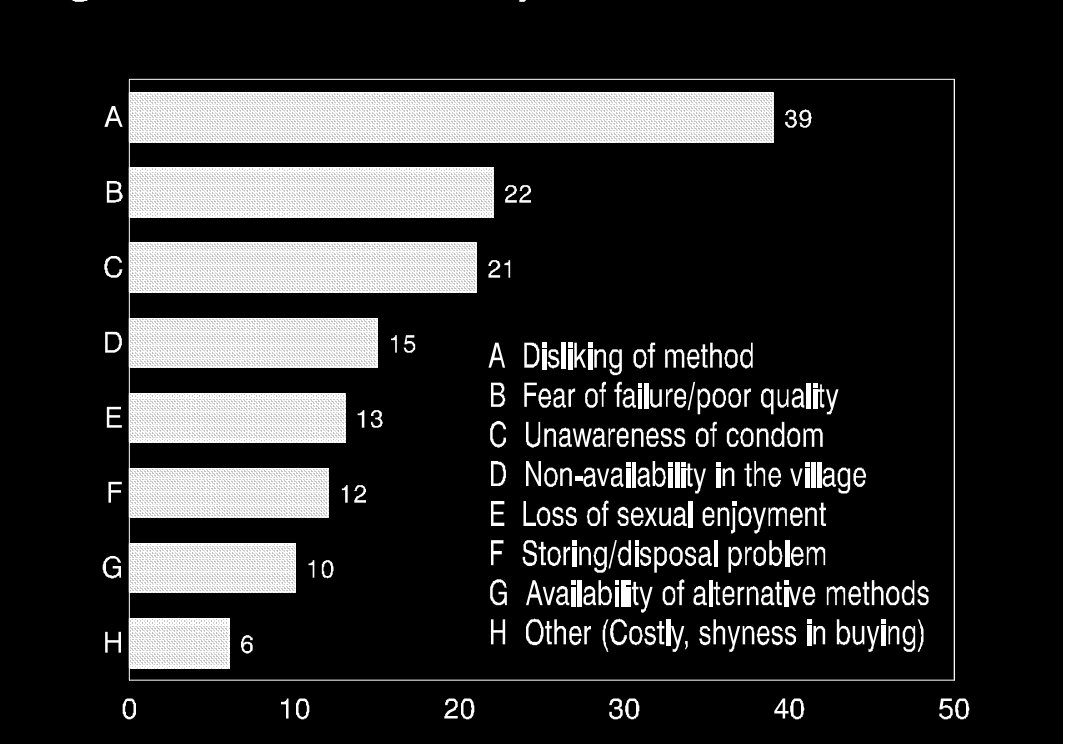
enjoyment (13 per cent), (f) storing and disposal problems/ children start playing (12 per cent), and ( $\mathrm{g}$ ) availability of other choice (tubectomy, 10 per cent). Many problems identified above are important and worth consider by the program managers. It is important to point out that availability of condoms from retail outlets in rural area is extremely low (the Population Council, 1995). According to a recent estimate only about 28 per cent of the villages in India have a retail outlet for condom and this proportion has not changed much during the last 10 years (Narasimhan and Khan, 1996).

Informal discussions with several men show that resistance on the part of men to use condom is strong not only because of the interruption it demands before intercourse for wearing it but also because of the management of condoms after the sexual act. For many men who do not have adequate privacy or bath room facility, post-intercourse management of condom is 'messy', 'dirty', 'repulsive' and 'problematic'. Stocking and disposal of condoms also appeared to be a serious problem. As one of the informants said:

"We hate when we see that condom used in the night by people is being played by children in the day time."

"People use condom and throw it outside house. It looks dirty."

"Where do we keep it in this one room house? Everything is seen by all. Sometime children take it out and use it as balloon. They call it as Bara balloon (big balloon)." 
"My children are now growing and keeping those things in home is difficult."

The poor quality of the condom resulting in unwanted pregnancies was mentioned by several men:

"I was using condom all the time still my wife became pregnant."

"My wife had to undergo abortion because condom failed."

Indepth case studies are required to assess how far these complaints are correct and to what extent failure of the condom is due to incorrect use of the method.

In India still most of the couples use contraceptives mainly to limit childbearing. Several available studies show that most of the couples who adopt sterilization had not used any other family planning method in their reproductive life (ORG, 1990; Khan and Patel, 1996). Similarly, analysis of the purpose of contraceptive use of couples who were using non-terminal methods reveals that majority of them were using it mainly for terminating childbearing (ORG, 1990). Thus, in India, where spacing is still an alien concept, the chances of increasing acceptability and use of condom, in face of the existing disliking for the method among men, is doubtful. To ensure higher acceptability of condom, the main target group should be young couples and marketing of the concept of 'safe sex' and 'spacing as key to sexual enjoyment', perhaps would be more effective. Awareness about STD and AIDS among men and women and the condom as a preventive measure could alter cultural bias against condoms both among men and women, and may increase the acceptability and use of the contraceptive (Green, 1990; Ringheim, 1993).

Suggestions by the male respondents for increasing condom use included: aggressive IEC campaign using radio/press and individual contact in all villages (34 per cent), free distribution of condom from different sources (32 per cent), focussed counselling of men about its correct use and benefits/removing misconception about the method (36 per cent), improvement in the quality of condom (10 per cent), and easy availability in all villages ( 9 per cent). About 15 per cent could not offer any suggestion. 


\section{Awareness of Legal Status of Abortion and its Approval}

An attempt was made to assess how men would react if, despite of desiring no additional child, their wives become pregnant. As Figure 12 shows about 63 per cent men felt that they would accept the child. About 25 per cent said that they would abort the pregnancy, while a small proportion (12 per cent) were uncertain about their action in such situation. The corresponding analysis for women respondents

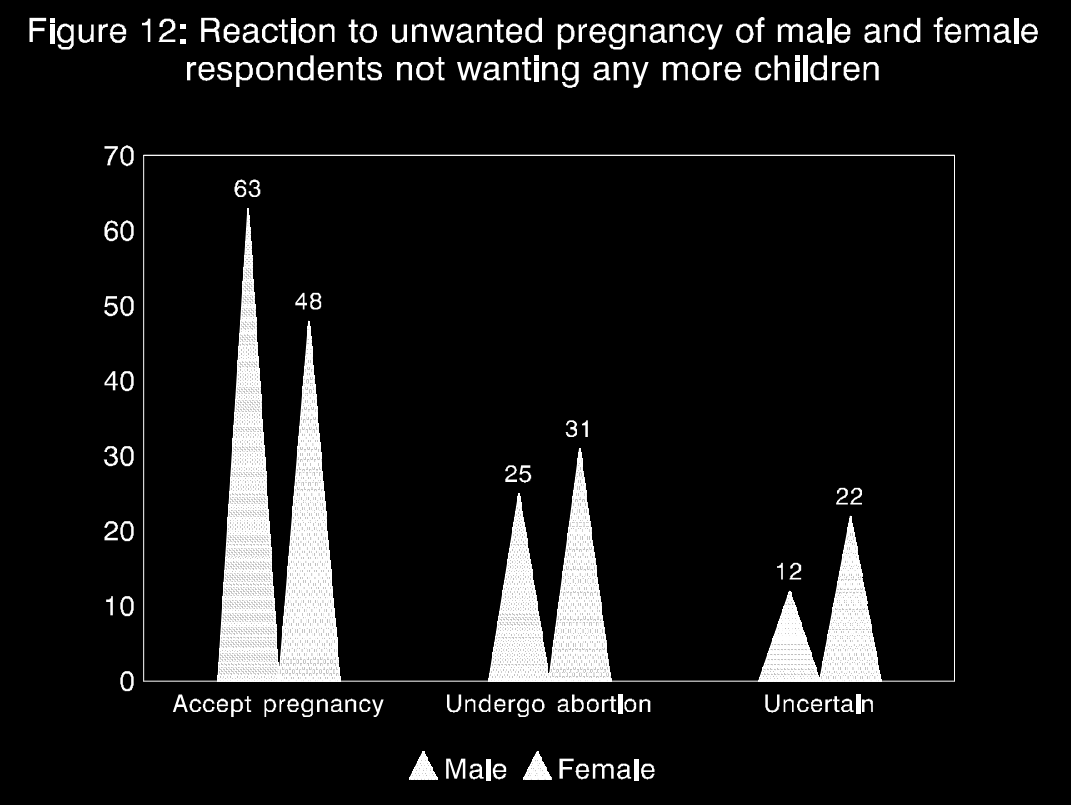
revealed that a relatively higher proportion of them favoured abortion (31 per cent) or expressed a state of uncertainty (22 per cent) because of their lack of control on such reproductive matters.

As seen in the earlier section, in about 49 per cent of the cases the men were of opinion that only husbands could decide whether the unwanted pregnancy should be aborted. Only in 6 per cent of the cases, they felt that in such matters women could take their own decisions. 
Abortion, despite being legally approved for more than two decades, has remained a sensitive issue and in general disapproved by the society. As a result, in desperation women attempt to abort their unwanted pregnancy using traditional and unhygienic methods, at times secretly which more often than not lead to serious health hazards. Often the women take these drastic actions because they are not sure how their family members,

particularly their husband, would react or whether they would approve of abortion. In the present study an attempt was made to assess how far men are aware of the legal status of abortion and if they approve of it for unwanted pregnancy. The analysis shows that only 22 per cent of them were aware that abortion was legal in India. 68 per cent believed that it was illegal, while the remaining 10 per cent did not know anything about it (Figure 13).

Probing on whether they approve of abortion, three-fourths of the 517 men answered negatively. Only a small proportion (10 per cent) approved of it unconditionally, while, another 15 per cent approved of it only under certain conditions like health problem of mother or pregnancy of unmarried girls (Figure 14).

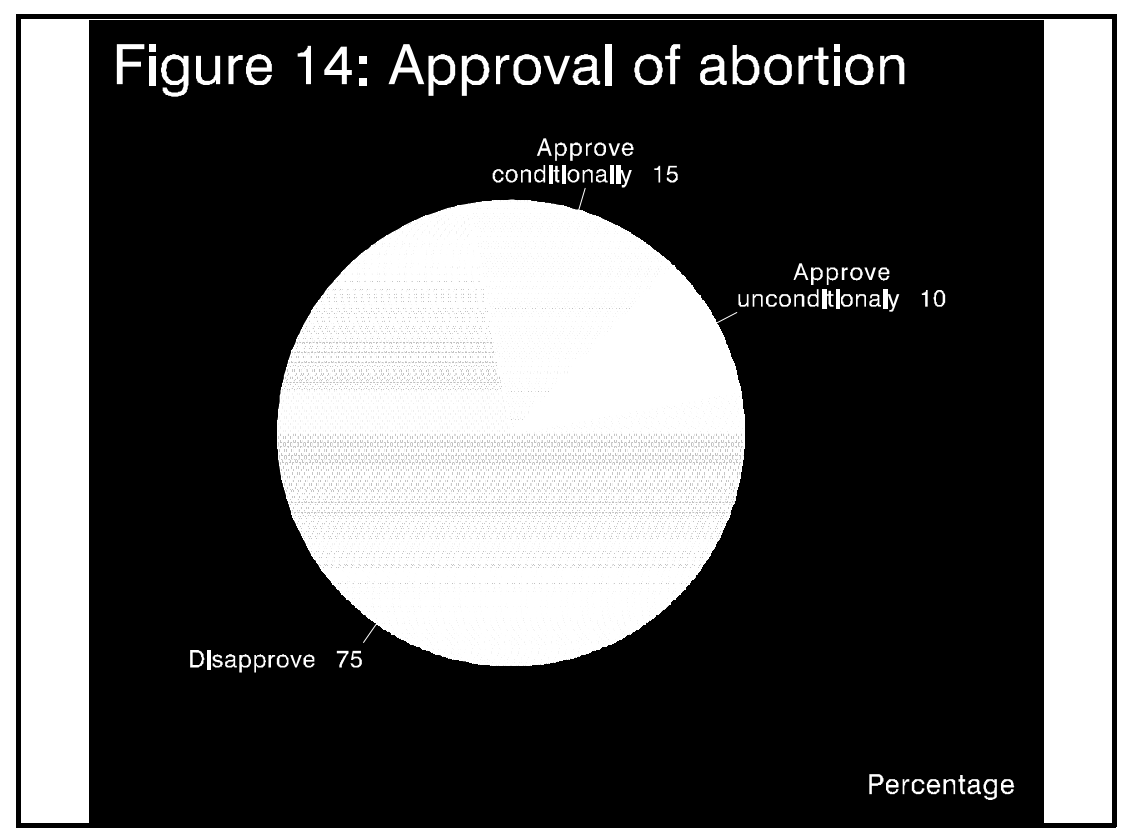


All the men who did not approve of MTP were asked to state the reasons for their disapproval of abortion. Their answers revealed that most of them disapproved abortion mainly on moral and religious grounds (Table 15). For instance, 71 per cent considered it a sin, while another 45 per cent perceived as killing of the unborn child "who are God's gifts" (22 per cent). Concern of the women's health as the reason for disapproving MTP was mentioned by only 12 per cent of the men interviewed.

Table 15: Reasons for disapproving MTP

\begin{tabular}{|l|r|}
\hline Reasons $^{*}$ & Percentage \\
\hline It is a sin & 71 \\
It is killing of the unborn child & 45 \\
Children are God's gifts & 22 \\
Against religion & 15 \\
Bad for women's health & 12 \\
Not good for society & 8 \\
\hline Total N & 388 \\
\hline${ }^{*}$ Multiple responses
\end{tabular}

Further analysis of whether awareness of the legal status of abortion helps in changing attitude of men towards MTP favourably showed that, a much larger proportion (35 per cent) of the men who were correctly aware of the legal status of MTP approved abortion as against those who were not aware that abortion is legal ( 2 percent) or believed that abortion is illegal (3 per cent) (Table 16).

Table 16: Approval of abortion by knowledge of the legal status of abortion in India

\begin{tabular}{|l|r|r|r|r|}
\hline & Approves & $\begin{array}{r}\text { Conditionally } \\
\text { approves }\end{array}$ & Disapproves & Total N \\
\hline Legal & 35 & 26 & 39 & 113 \\
Do not know & 2 & 41 & 57 & 58 \\
Illlegal & 3 & 8 & 81 & 346 \\
\hline
\end{tabular}

CORT reported a similar relationship among the women in Bihar (CORT, 1996). This indicates that if the men are informed correctly about the legal status of MTP, it may help in changing their attitude towards abortion favourably. Such a change in the attitude of people, particularly men, is essential to ensure that women could have easy access to safe and hygienic abortion services. As we have seen in earlier sections, unless men approve, women cannot abort their unwanted pregnancy. 


\section{References}

Aguma, Anna (1996). Finding the Right Sexual Health Services for Young Men. Planned Parenthood Challenges. No.2, 1996.

Bruce, J. (1994). "Reproductive choice: the responsibilities of men and women". Reproductive Health Matters No. $4,68-70$.

Centre for Operations Research and Training (CORT) (1996). Small Family by Choice: Family Planning Programme in Bihar: Baseline Survey of Gaya and Nawada. Monograph, CORT, Baroda.

Centre for Operations Research and Training (CORT) (1995). Small Family by Choice: Family Planning Programme in Madhya Pradesh: Baseline Survey of Sagar, Bhopal and Vidisha Districts. Monograph, CORT, Baroda.

Cleland, J. (1992). London School of Hygiene and Tropical Medicine, Personal Communication, cited in Ringheim, K. "Factors that determine prevalence of use of contraceptive methods for men". Studies in Family Planning, 24(2), 1993.

Davies, J., Mitra, S. N. and Schellstide, W. P. (1987). "Oral contraception in Bangladesh: Social marketing and the Importance of Husbands". Studies in Family Planning, 18(3); 157-168.

Green, C.P. (1990). "Male Involvement Programs in Family Planning: Lessons Learned and Implications for AIDS Prevention". Geneva, Switzerland, World Health Organization/Global Programme on AIDS (unpublished).

Green, C. P., Cohen, S. I. and Ghouayel, H. B. (1995). "Male Involvement in Reproductive Health, including Family Planning and Sexual Health". Technical Report, 28, UNFPA.

International Institute for Population Sciences (1994). National Family Health Survey. IIPS, Bombay (22 volumes, one volume for each State of India).

Khan, M. E. (1979). Family Planning among Muslims in India. Manohar Publications, New Delhi.

Khan, M. E. and Patel, B. C. (1996). "Level of Unwanted Pregnancies and Its Consequences". Paper presented in IUSSP Seminar on Socio-cultural and Political Aspects of Abortion from an Anthropological Perspective held on 25-28th March, 1996.

Khan, M.E., Irfan Khan and Nepur Mukerjee (1997a)

Khan, M.E., Irfan Khan and Nepur Mukerjee (1997b). Involving Men in Safe-motherhood. Special Issue of Journal for Family Welfare on Safe Motherhood, June 1997.

Maitra and Associates (1985). Bangladesh Contraceptive Prevalence Survey - 1983.

Mason, K. O. and Taj, A. M. (1987). Differences between women's and men's reproductive goals in developing countries". Population and Development Review, 13(4): 611-638.

Narasimhan, R. and Khan, M. E. (1996). Social Marketing of Condoms in India: A Trend Analysis for the period 1981-91. Spacing as an Alternative Strategy: India's Family Welfare Programme. B.R. Publishing Corporation. 
Operations Research Group (1982). Second All India Family Planning Survey. Monograph, ORG, Baroda. Operations Research Group (1990). Family Planning Practices in India: Third All India Family Planning Survey. Monograph, ORG, Baroda.

Piet Pelon, N. J. and Rob, U. (1996). "Male Involvement: A challenge for the Bangladesh National Family Planning Program". Policy Dialogue, Population Council, Bangladesh, No. 2.

Piotrow, P. T., Katherine, A. T., Jose, G. R. II, Sung, H. Y. and Benjamin, V. L. (1994). Strategies for Family Planning Promotion. World Bank Technical Paper 223, Washington, DC, World Bank, 1994.

The Population Council (1995). District Level Baseline Survey of Family Planning Program in Agra, Uttar Pradesh. Monograph, New Delhi.

Ringheim, K. (1993). Factors that determine prevalence of use of contraceptive methods for men". Studies in Family Planning, 24(2): 87-99.

SIFPSA and The Population Council (1995). District Level Baseline Survey of Family Planning Program in Uttar Pradesh. Monographs, New Delhi (15 volumes, one for each study districts: Sitapur, Gonda, Gorakhpur, Rampur, Shahjahanpur, Jhansi, Lalitpur, Jalaun, Pithoragarh, Nainital, Tehri-Garhwal, Meerut, Ghaziabad, Jaunpur and Kanpur).

Schuler, S. R., Hashemi, S. M. and Jenkins, A. H. (1995). Bangladesh's family planning success story: A gender perspective. International Family Planning Perspectives, 21(4).

Spieler, J. (1991). Men in Family Planning, speech to AVSC Staff Workshop, New York. Policy Dialogue, The Population Council, Bangladesh, No. 2.

UNFPA, 1995. "Male Involvement in Reproductive Health, including Family Planning and Sexual Health". Technical Report, No.28. 